\title{
Dating and Sex among Emerging Adults in Nepal
}

\begin{abstract}
Social and cultural changes in Nepal, including better communication facilities and transport, more urbanisation and a rising age at which people marry, have created more opportunities for young people for "dating." Our qualitative study explores whether the existence of dating cultures influences young people's sexual behavior in Nepal. Focus group discussions with a total of 75 participants and 31 in-depth individual interviews were conducted among young people in Nepal. Most urban and rural young people liked the dating culture. Although it is a new kind of culture in Nepalese society, it is gaining popularity. The mass media were regarded as encouraging and creating an environment for dating. Most participants believed that dating culture encourages pre-marital and extra-marital sexual behavior. We underpin our findings by linking it to the "emerging adulthood" framework. In term of public health we recommend that dating practice should be discussed in formal and informal education to promote safer sex.
\end{abstract}

Key Words: Social change, culture, sexual health, developing countries

\section{Background}

Literature about dating and sexual culture in Nepal is fairly rare, which is not unexpected in a society where talking about sexual matters is still considered to be a taboo (Dahal, 2008; Mathur, Malhotra, \& Mehta, 2001). Health workers and teachers are also reluctant to discuss sexuality and reproductive health. Pokharel and colleagues (2006: 157) found that teachers "did 
not want to deal with such sensitivetopics and feared censure by their colleagues and society". It is also frequently observed that health and education staff in Nepal use English or Sanskritderived Nepali words as a way of talking about sexual and reproductive health issues without having to use everyday language (Pigg, 2002).

Attitudes towards sex and sexuality in Nepal are largely derived from ancient Hindu texts (e.g. the Veda, Ramayana and Mahabharata) and Buddhism (Francoeur \& Noonan, 2004). These texts provide the moral views on sexuality and marriage in a country where eighty percent of the population is Hindu and Buddhism is the second most popular religion. Although sexually explicit material (pictures and statues) can be seen in temples and historical buildings in Nepal, sex is a mutual and private affair between a married couple, where husband and wife pleasure each other equally. At the same time Nepal has a rich and diverse cultural heritage (Regmi, Simkhada, \& van Teijlingen, 2008), where different cultural groups have their own norms and values towards marriage, but arranged marriages are still the norm (Schick, 1999). Usually in this traditional marriage system the bride moves into the grooms' house after the marriage.

Many people do not want their daughters or sisters to have pre-marital sexual relationships. Burbank (1994) found that Nepalese parents in many rural areas even discourage their daughters from meeting with or talking to boys. According to Waszak and colleagues (2003: 83) 'Girls 'caught' talking to boys in public places are criticized and sometimes punished by parents and the community for being characterless." Hence, sexual activities before and outside marriage are often not acceptable (Dahal, 2008; Okazaki ).

However, with increased exposure to global television and radio networks, movies and the modernisation of society and culture, the young generation has taken a more positive turn in terms of attitudes towards sexual relationships. There is also a growing trend towards pre-marital 
sexual activities among young people in Nepal (Adhikari \& Tamang, 2009; Gubhaju, 2002; Prasai, 1999, Regmi, Simkhada, \& van Teijlingen, 2010). For example, a recent study in Nepal (FHI, 2001) reported that $15 \%$ of adolescent boys engaged in premarital sexual intercourse. Another study among young factory workers in Kathmandu showed that $35 \%$ of unmarried boys and 16\% unmarried girls have experienced sex (Puri \& Cleland, 2006). Likewise, a study among college students of Kathmandu has found that almost $40 \%$ of young men reported having had premarital sex (Adhikari \& Tamang, 2009).

There is evidence of the impact of modernisation and globalisation on sexual behavior (Altman, 2004; Arnett, 2002; Bhadra, 1999). It is now widely believed that boys and girls in Nepal are more comfortable being around and dating each other (Rana, 2004) at a much earlier age than they were in the recent past. It can be argued that this change may partly due to globalization and modernization, particularly through mass media. Until 1995, governmentowned Radio Nepal and Nepal Television were the only legal forms of mass communication, which delivered a limited range of programs (Library of Congress, 2010). However, after 1995 private radio stations, television channels and newspapers entered into the mass communication business. These media often deliver youth-oriented programs. There has also been an increase of sexual images as part of widely available Indian television channels which includes western programs popular among young urban people (Francoeur \& Noonan, 2004).

As part of the general modernization in Nepal literacy levels have increased particularly over the last two decades. For example, male literacy in boys aged six and over had reached $65 \%$ in 2001 (from 34\% in 1981). The growth in the female literacy rate has been even more spectacular as it trebled in the same period from $12 \%$ to $43 \%$. However, gender composition of higher secondary school pupils is unbalanced with girls representing only $38 \%$ of all pupils, and 
the imbalance is even greater at university level where women represent only $33 \%$ of all students (Sinha 2008).

Young people and sexual matters regularly attract the attention of the Nepalese media as well as that of policy makers, the general population and health researchers (New Era/MoH, 2006; Stone, Ingham, \& Simkhada, 2003; Thapa, Davey, Waszak, \& Bhadra, 2001; UNFPA, 2004). However, dating is a relatively new phenomenon in Nepal, and no previous single study has explored the relationship between dating and young people's sexual behavior. Dating in this paper is defined as a meeting between young women and men for romantic and sexual purposes. It could be a chance meeting, leading to a short-term relationship, or a planned meeting, which explores and develops into a longer-term partnership.

In the past, the transition from childhood to adulthood was associated with early marriage and childbearing. This has dramatically changed in many developed and developing societies resulting in an extended period before marriage (Arnett, 2010; Choe, Thapa, \& Mishra, 2004; Gubhaju, 2002). Bott and colleagues (2003) suggested that as many South Asian boys and girls spend more years in education and marry later, they have more opportunities to spend time in intimate (sexual) relationships before marriage. Such opportunities may also result in forced sexual activities, unwanted pregnancies, induced abortion and Sexually Transmitted Infections (STIs) including Human Immunodeficiency Virus (HIV) (Burke, Stets, \& Pirog-Good, 1988; Hettrich \& O’leary, 2007; Muñoz-Rivas, Grana, O’leary, \& Gonzalez, 2007).

Research on young people's sexual behavior often focuses on identifying critical factors such as peer pressure, drug use and multiple partners which are considered to be risky sexual behavior (Han, Choe, Lee, \& Lee, 2001; Puri \& Busza, 2004). Until recently, most Nepalese studies ignored the influence of dating practices on young people (Aryal \& Adhikary, 2003). 
This qualitative study aims to explore young people's attitude towards dating and the relationship between dating and sexual practices.

We present our findings in the light of the developmental framework of 'emerging adulthood' (Arnett 2002; 2010; Nelson, Badger, \& Wu, 2004). This theoretical approach argues that in a globalised world transitions to fully fledged adulthood are occurring at a later age then in the past (Arnett 2002). With social and cultural changes occurring in Nepal this theory can help frame the developments mentioned above in a global and historical perspective. In Nepal and other developing countries, emerging adulthood is not a normative life stage, because entering marriage, parenthood, and adult work begins in the teens or very early twenties (Arnett, 2010). However, Arnett (2010) has proposed that in developing countries emerging adulthood exists among the minority of young people who are part of the middle class. Our sample consisted mostly of college students, so the emerging adulthood framework is appropriate for this study.

\section{Method}

In the summer of 2007 we conducted focus group discussions (FGDs) and in-depth interviews among married and unmarried young people aged 15-24. Qualitative methods are recommended for research on sexuality (Firth, 2000; Silverman, 2006) and have previously been applied to researching sexuality and other sensitiveissues (Puri \& Busza, 2004; Reid \& van

Teijlingen, 2006; Regmi, Simkhada, \& van Teijlingen, 2010; Simkhada, Bhatta, Regmi, \& van Teijlingen 2010; Thapa, Davey, Waszak, \& Bhadra, 2001).

\section{Participants}

Participants of the FGDs and in-depth interview were selected purposively (Bowling, 2002) from urban and rural areas of Kathmandu and Chitwan districts. These are fastest growing 
districts in Nepal, which contain more modern facilities than other districts in the country. We selected four university colleges and one youth club from Kathmandu and three colleges and two youth clubs from Chitwan. Educated participants were gathered with the help of college staffs whereas school/college drop-out participants were selected with the help of communities and youth clubs. Informal meetings with stakeholders were held to seek assistance in recruiting participants. Interviewees were purposively selected based on their residence (urban \& rural), age (15-24), education (school/college going \& school drop-out), dating practice (previous experience) and sexual history.

Altogether ten FGDs (5 male \& 5 female) were carried out with an average of seven participants each; four consisted of college students, three of school drop-outs and three contained a mixture of college and university students (Table 1). Five FGDs were conducted with rural participants. Most participants were aged 18- 22 years.

In the in-depth interview, fifteen participants were from the age group 21-23 and nine were from age 18-20 (Table 2). Four-respondents were at school (Grade 1-10), 24 respondents were from college level (certificate level to undergraduate) and three interviewees had completed a Masters degree.

\section{Procedure}

In Nepal it is not possible to conduct interviews about sexual matters with the opposite sex. There is evidence that the interviewer's gender does have a significant influence on responses to sensitive questions in less developed countries (Axinn, 1991). So, same sex researchers conducted FGDs and in-depth interviews. Hennink (2007) argued that providing training to the researchers helps them to obtain high quality data. So, the researchers and FGD 
moderators received one-day training explaining the research aims, method of data collection, equipment use, structure of the questions and target groups.

A semi-structured discussion guide was developed in Nepali using a question route format. Such guide helps to provide consistent information and also improves the comparability of information among groups (Hennink, 2007). The question route incorporated issues of partnership formation, dating practice and sexual behavior. Two FGDs (1 male \& 1 female) and four in-depth interviews ( 2 male \& 2 female) were carried out in Kathmandu to pre-test the questions. All FGDs and interviews were conducted in Nepali, in a comfortable environment; often a closed room to assure confidentiality (Twinn, 1997). They were tape recorded and generally lasted one to two hours. Two male in-depth respondents declined to take part in the interview and one female respondent withdrew during her interview. The reasons they were not willing to participate were personal problems and lack of time.

\section{Coding}

Transcriptions were made based on the original tape recordings (McLellan, MacQueen \& Neidig, 2003) and then translated into English. The first author translated all transcriptions into English and the second author, who is also a native Nepali speaker, cross-checked the translated version (Pitchforth \& van Teijlingen, 2005). Any disagreements were discussed in detail between the authors for appropriate translation.

Data were cleaned and coded prior to analysis, and organised with the help of NVIVO software. A thematic approach was followed in the analysis (Forrest, van Teijlingen \& Pitchforth, 2005; Ryan \& Bernard, 2003). Transcripts were read and coded by two researchers. The first author analysed all transcripts and the other authors acted as second coders. Any discrepancies in the coding were resolved by discussion. Relevant quotes are presented to 
illustrate the key themes. Ethical approval was granted by the Nepal Health Research Council, and consent was taken from participants prior to the study.

\section{Results}

The following themes were identified, some of which are overlapping: (1) attitude towards dating; (2) opportunity for partnership formation; (3) girls find it hard to make the first move; (4) factors encouraging dating; (5) dating place; (6) factors encouraging premarital sex and the role of dating; (7) dating with extramarital partners; (8) barriers to testing; and (8) concerns about safe sex.

\section{Attitude towards dating}

Most participants had a very positive attitude towards dating which they felt allows them to share love, feelings, pleasure and problems with their partners. Some male respondents also argued that dating provides opportunities for sexual pleasure. Married participants and school drop-outs also liked dating, although they were in favour of dating for a particular purpose only. These were usually linked with financial benefits for women and sexual pleasure for men. Most of the urban participants and the majority of the rural boys had some dating experience with the opposite sex. Almost all considered dating as a normal act, for example:

“... it is a good thing but it should be practised properly...I have also gone many times... I always wanted to see and meet him in a peaceful place." (Interview, married woman, age 21)

“... I like it... I have gone on dates with my girlfriend many times and even spent a whole night with her. In my view, it is a good practice. It allows us to share our feelings. You know, in Nepal, we cannot go to the girl's home directly and girls cannot come to our 
home either. We have to share our feelings somewhere else so we decide to go for a date." (Interview, unmarried man, age 20)

We were surprised that the term 'dating' is very familiar among participants although it is a relatively new phenomenon in Nepal. It is also interesting to note that there are no Nepali or local words for it, instead young people used the English term 'dating'. Most rural participants also clearly understood the word without probing, although some linked the word 'date' to calendar or day. Overall our research suggests that dating is a common practice among many urban and some rural Nepalese youths.

Most thought that parents and community leaders (i.e. the older generation) still have negative attitudes towards dating. Some younger or better educated participants thought that some parents might view dating positively. Participants also believe that people in the community would view dating positively if it is practised by emerging adults rather than adolescents, for example:

"People do not like teenagers' love because they go there for different reasons. Even if I had such experiences, my parents would not have been happy. I think they still have traditional thoughts. Now I am matured and I am working. They treat me differently. When I was young, my parents used to say that I should marry a boy from the same caste which I belong to... Now they have changed and say that if you are happy then it does not matter." (FGD, unmarried urban women)

\section{Opportunity for partnership formation}

FGDs and in-depth interviews showed that most young people meet and form partnerships with the opposite sex while they are at college or in their community. Rural participants found it difficult to form partnerships at school, because of the fear that teachers or 
their family will find out and punished them. Educated participants were more likely to find partners at school and college whereas uneducated participants tend to meet partners in the community. For uneducated young people, local community events such as marriage ceremonies, worships and fairs/festivals offer the main opportunities to establish partnerships. Rural young people also reported that they sometime meet partners whilst working in the field or forest (e.g. to collect woods or grass).

"In rural places, boys and girls meet while they work in the fields. We have to go the jungle for grass and wood. Sometime, we find girls on the way." (FGD, school drop-out men).

Most young people agreed that there is a better chance of forming partnerships with the opposite sex if there are frequent opportunities to meet, as exemplified by the following quotes:

“...I had actually started to love him when I went to college after my school. He used to sing very nicely. ... We had sung during our school farewell programme. We had to rehearse for this program and used to meet frequently at school. One day he wrote a letter. I also liked him." (Interview, married woman, age 22)

"I used to stay near his shop and I used to get food and other items from his store...later on we became closer and started to love each other." (Interview, unmarried woman, age 23)

Our study also found that communication facilities such as mobile phones and the internet have some impact on finding partners. Most urban boys and girls reported that young people spend lot of time chatting on-line in cyber cafés to find partners. Both urban and rural participants frequently noted the importance of the role of peers in selecting partners, since peers 
may provide biographical information about potential partners or supported them in forming partnerships.

\section{Girls find it hard to make the first move}

Most participants reported that boys always make the first move and encourage girls to go on dates, although a few urban boys believed that girls may act first. We found different views among some urban girls. Their perception was that there is an equal chance of boys or girls make the first move. It is interesting to note that some rural girls also agreed with this view. The majority of girls believed that sometimes boys reject their love so there is a fear being the first to ask. In addition, rural boys and girls agreed that most girls are very soft and weak-hearted in nature and cannot express their feelings of love. Most rural participants expressed the opinion that girls feel shy and nervous about discussing relationships with boys. Some suggested that if a girl makes the first move then boys might take it differently, for example:

“...boys do not take it positively if we make the first move. We can ask them if we want to do that...this is our social problem. In most cases, boys act first. They always push for it." (FGD, unmarried urban women)

\section{Factors encouraging dating}

Most urban respondents considered dating to be natural and normal; it was seen as an activity which was encouraged by the mass media (TV, radio, newspapers, movies, Internet). Participants generally agreed that young people in Nepal learn about love, dating and relationships from the media, e.g.:

“...They learn many things from Nepali and Hindi movies. ... how to persuade girls, how to talk to girls and how to go on dates ...movies are encouraging young people to do that." (FGD, rural men) 
Some urban boys reported that economic status also encouraged dating, for example:

"...If you have money then you get girls to agree to dates. If you ride Raj-doot (old fashioned motorbike) bike, no one goes with you. You should ride expensive and deluxe bikes to find beautiful girls." (FGD, urban men)

Most urban boys said that young people go on dates to have fun. Some rural participants also shared this notion. Many reported that the lack of freedom in a rural community forces them to go to isolated places to meet.

"When young couple cannot share love within the community, then they have to find alternatives." (FGD, rural men)

Peer influence was a very important factor in decisions on love and dating. Rural and urban male participants argued that boys want to go on dates because of their peers' encouragement. There is a demonstration effect of peers. Young urban boys argued that some boys date girls just to show off to their friends.

Some believed that unmarried girls involved in premarital sex expect some financial reward from boys. Dating is sometime linked with gifts particularly for unmarried and unemployed girls. Most argued that unmarried and unemployed girls may go on dates with boys (married or unmarried) for financial advantages.

We never pay bills at restaurants, cinema or even for gift items. We feel financially safe if we are on a date with boys (laughs). It also helps to ease our financial problems. Even if we want to pay, boys do not allow to do that ....but some girls are very greedy and make multiple boyfriends." (FGD, urban girls).

Most boys reported that there is also the possibility to date married girls for sexual pleasure and money, for example: 
“...it is a matter of desires. There is also a chance of having some financial support. We get some support from married women. If they are rich and their husbands are not at home then they support young boys. It is a matter of give and take. I have plenty of friends who go with married girls. These girls get satisfaction and boys get money. Whatever they ask, they get." (FGD, urban men)

\section{Dating Place}

There is a rural-urban divide regarding the localities used for dating. Most urban participants liked crowded places such as restaurants, inns, hotels, cinemas and parks. Some urban young people used public transport (buses) for dating. Rural participants seem to prefer quieter areas such as the jungle, parks, lodges, schools or temples and the riverside, although some boys preferred to go to nearby towns. Both urban and rural participants believed that boys and girls also meet in private rooms, hotels and resorts. Moreover, most rural girls preferred to go to temples for a date as others may not guess their intentions. Economic status, time and mode of transport were most frequently reported determinants to selecting dating places.

“Most couples prefer peaceful dating places. They don't want to be seen by other people. Most of the time, I like to go to parks and restaurants." (Interview, urban woman, age 23)

Most boys argued that couples might go to isolated dating places if they plan sexual intercourse, for example:

"When they go to quiet places like the jungle or rooms, they become very close to each other... No one can stop them doing this. When we went to dating places, we also had similar experiences (laughs)." (Interview, married man, age 23).

Factors encouraging premarital sex and the role of dating 
Our findings show that most girls preferred long-term relationships with boys whilst boys preferred short-term relationships. Most boys wanted to find girlfriends to fulfil their sexual desires. Urban boys claimed that unless they find girls, they visit sex workers. For example;

"Even if we dare to share with them (girls) about our sexual desires, they may reject us. Hence in some occasion, we boys have to find alternatives because there is no sure that girl become ready for sex. Sex workers are always there for it." (FGD, urban men)

Findings also indicate that curiosity and pleasure were the most frequently reported encouraging factors for premarital sexual practices. Some participants reported financial motives for sexual partnerships. Press and electronic media such as satellite TV, movies, magazines and porn CDs were also frequently reported as factors encouraging premarital sex.

“...Boys keep porn CDs. We exchange and view it... we borrow porn CDs from friends. We learn many positions from these CDs." (FGD, urban men)

"We watch $T V$ and films, read papers and listen to the radio... It is all about sex. We become emotional and attempt to do such things. There are too many naked pictures found in papers and on the net. It really affects us." (Interview, urban women, age 20)

Educated urban participants shared the view that sexual activities are natural and argued that no one needs to learn about sex. Most participants agreed that boys are the ones to initiate sexual relations. Girls shared that if boys and girls believe in each other then they may have sex. Most of the boys and even some girls also shared that sexual opportunities should be taken, when they occur:

"...if you believe in someone very much then you can have sex before marriage. It makes no difference. We don't know when we die, do we? So we have to grab the opportunity." (Interview, unmarried woman, age 20) 
“...we had sexual relations before our marriage...as we both believed in each other so I also agreed...on Valentine's Day. I did not hesitate to do that because I was so sure that he will never break our relationship. He never pestered me." (Interview, married woman, age 24)

Most FGDs and in-depth interviews suggested that dating encourages early sexual practices. Though most shared that young people date to share love, some urban and rural participants also thought that young people date for sexual purposes. Most argued that whether or not sexual intercourse takes place is determined by location, reason for dating and the character of the partners. All participants agreed that there is a higher chance of sexual acts taking place if dating occurs in isolated places like the jungle, hotels and private rooms. Here are some examples:

"...If they go to a quiet place then there is a high chance of having sexual relations. If there are only two people ... even if they are shy and feel afraid, they cross the limit. They may be so curious about that whenever they get the chance, they may act." (FGD, urban women)

"...if they want to have sex then they go to isolated places. If they have gone to a cottage or lodge then you can easily guess that they might have sex there." (FGD, school dropouts men)

Generally most boys were positive towards premarital sex and some girls were very negative. Rural married women were more likely to consider these activities as illegal and a sin. "Premarital sex is a crime. I take it very negatively. It happens because of the physical attraction. People do it just for pleasure. They don't care much about future."(FGD, rural women). 
"Most of the young people perform sex before marriage but it is not a good thing. If they do it before marriage then I think they are sinners. "(FGD, school drop-outs women).

However, most boys and urban girls accepted premarital sex if performed safely and with care.

“...I don't say it is a bad thing. If you do it carefully with high precautions then I think it is nice. I am very positive towards premarital sex." (Interview, married man, age 23)

\section{Dating with Extramarital Partners}

Both rural and urban participants believed that extra-marital dating is common. Some urban participants also had a positive attitude towards extra-marital dating, for example:

"It is not a big deal... We think that it is just an understanding between husband and wife. We should be very liberal in this matter. Unless and until we engage in sexual activities with other married women then it is okay to go date...but we should also be responsible to our families." (FGD, urban men)

Urban boys reported that unmarried boys like married girls thinking that they look very beautiful with jewellery and ornaments. Rural participants said that married women date other men when their husbands are away. Similarly, many urban participants shared that married boys and girls date extra-marital partners if they are sexually dissatisfied or if their marital partners are too busy. The following long quote illustrates, not just one of the reasons for a married woman for dating, but also the consequences this can have on her further life:

“...I had made a mistake at that time. When I went with someone I should have stayed with him... My husband used to work at another place. I used to feel lonely at home. When I met another man nearby my home, I developed relationship with him and started feeling relief. We used to work together in the field. Later, when my family found out 
about it, none of the family members supported me. ... I knew that I was married but still I went with him. When everybody blamed me...I told him everything and asked him to marry me, but he refused. He was also married with two children. He suggested me to marry with another man. Later, I knew that this man was his relative. I re-married after seven/eight months of my first marriage." (Interview, school drop-out woman, age 20)

Participants also argued that if wives are less educated and always stay at home then their husbands are likely to date other women. Most FGDs and interviewees agreed that extra-marital dates are only for sexual pleasure. Here are some examples:

“...if wives are too old then they try to find Potili (young) girl for new taste." (FGD, urban women)

"I am married, however, if I see someone who is very hot and nice...I can be attracted by her. If I get opportunities to see her regularly, there is a chance of forming sexual partnership with her. I don't think I can control myself because of just being a married."(Focus Group, urban males)

\section{Barriers to dating}

There are some differences among urban and rural participants regarding barriers to dating. Urban participants viewed time and money as the major barriers to dating, whereas rural participants shared that family, community and low-economic status are the main barriers. Most rural girls said that their family do not allow them to date. Some rural participants also reported that lack of dating places such as parks and quiet places are barriers. Other barriers reported included transport, shyness, unfavourable weather, strikes, teasing by friends and lack of trust between partners. For example: 
“...I think economic problem is one of the reasons. In addition, some people are scared of the community people." (FGD, rural men)

"I was called by my girlfriend but I did not have money at that time so I cancelled it. I had planned for another day (laughs). We boys never say that we don't have money...we often lie if such a situation arises." (FGD, urban men)

\section{Concerns about safe sex}

There are mixed views on safe sex. Most participants were very positive towards safe sex, although some boys seemed not to be very serious. They believe that using condom reduces sexual pleasure. Participants agreed that they use alcohol particularly when they date in isolated places such as cabin restaurants and lodges. We also found some link between alcohol consumption and sexual behavior. Some highlighted that alcohol consumption leads to unsafe sex, for example;

“...we could not even remember to use a condom...I did not know what had happened...we both drank...so maybe...we saw nothing at that time." (Interview, married woman, age 24)

Most boys agreed that girls show more concern. Girls also perceived that they were responsible for safe sex because they have to face the physical, mental and social consequences. “...I think girls ask boys first...if boys refused to use it (condom) ...girls may refuse to have sex." (FGD, rural men)

“...Girls are more responsible for safe sex...they think about the future. Boys are not so serious. They can leave girls at any time...I know some girls are different and they become ready to face any challenges." (FGD, rural women) 
“...I think girls show more concern ...they directly face the consequences of unsafe sex so they show more concern... Boys will have no symptoms even after unsafe sex but girls may get pregnant and everybody can mark her." (Interview, unmarried man, age 21)

Most of the educated participants agreed that both boys and girls should be concerned about safe sex, e.g.:

“...all unmarried boys or girls should show concern for safe sex. Even if you are in true love, you should not take any risks. For example, I am just 19 and studying. I am not interested in having a baby right now ... I don't even know whether my boyfriend has any disease or not...if you really want to have sex then it must be safe." (Interview, unmarried woman, age 18)

Girls argued that they have less negotiation and decision-making power than boys. The majority agreed that boys should bring condoms and girls should encourage their use, e.g.:

“...Girls also show concern but it's up to boys...even if they have some resolve, boys can break it very easily...girls believe boys very much so I think boys have more responsibility for safer sexual practices."(In-depth Interview unmarried man, age 21)

\section{Discussion}

This is one of the first studies of dating among young people in Nepal. It explores the perception and practice of dating and its relation to sexual practices. Clearly young people in our study have a positive attitude towards dating, and most believed that many other young people are currently dating. This suggests that dating is becoming more common despite the negative attitudes of parents and the community (Burbank, 1994; Waszak, Thapa, \& Davey, 2003).

Our findings reveal that young people form opposite sex partnerships while they are in school, college or in their community. Rural young people have fewer opportunities for sexual 
partnership formation and they use occasions such as cultural or religious programs. Indeed, traditional Nepali culture is predominant among rural populations, with their often more conservative religious beliefs. Perhaps, young people easily get permission from parents to go to such programs and use them to establish partnerships.

There were gender and geographical differences in the views on dating. One possible explanation is that most urban people are better educated and generally have more liberal views on friendship between members of the opposite sex. They are also more likely to have greater independence and lower parental supervision. Thapa and colleagues (2001) observed that bettereducated parents allowed both sons and daughters to interact with the opposite sex. Low parental supervision has also been linked with increased sexual behavior (Hennink, Diamond, \& Cooper, 1999).

Surprisingly, rural people equally liked the dating culture although they reported more barriers. Living in a rural community in Nepal typically provides more opportunities for parents, teachers and people in the community to monitor and control dating among young people as was observed in rural Thailand (Liu et al., 2006). Some rural girls in our study viewed dating and premarital sex negatively.

Most participants agreed that girls find it hard to take the initiative in starting a relationship and that boys often make the first move. Nepal has a patriarchal society where men are the decision-makers and hold positions of power and prestige, and women have little power and choice, as is common in South Asia (Ali, Ali, Waheed, \& Memon, 2006; Garg, Sharma, \& Sahay 2001; Jejeebhoy, 1998; Poudel \& Carryer, 2000). These situations may force young women to sustain silence, which extends to discrimination in proposing love and sex. 
Our findings also suggest that rural girls are less likely to be able to share the feeling of love with partners, whereas urban girls seem to be more open in such matters. Perhaps, greater access of mass media in urban areas may have attributed to urban youths sharing love and sex. There is also some evidence that the process of urbanisation and the increasing influences of modern globalised cultural concepts on especially the young are responsible for the breakdown of traditional customs (Villarreal, 1998). It can be argued that globalisation is experienced with a greater intensity by urban young people than those living in rural areas (Arnett 2002: 777). Since globalisation promotes the spread of 'emerging adulthood' (Arnett 2002), it helps us to understand the growing dating culture in Nepal, since young people who, a decade or so ago, would have been married by the time they reached the age of 20 , are now in higher education, marrying much later and forming sexual relationships before marriage. These delays in entering the job market and marriage are signs of the postponing of adulthood and hence extending the period in life called emerging adulthood.

Boys and girls engage in dating for a variety of reasons. Girls in our study tended to want a long-term relationship (e.g. marriage) whereas most urban boys concentrated more on shortterm goals such as having a girlfriend of physical beauty and having intercourse, which is consistent with previous studies (Coombs \& Kenkel, 1966; McCabe, 2005). These findings reveal that many young people in urban areas view love as an important motivational force for participation in sexual activities.

There was some evidence that increased exposure to urban values, better transportation facilities, peers and mass media may encourage young people to become involved in dating, as found elsewhere in Asia (Hennink, Rana, \& Iqbal, 2005). Our study documented that activities like romance and kissing are observed (and copied) from films and cable television. Our 
participants also frequently reported the importance of mass media for better sexual health. This suggests we should perhaps use the mass media for sex and relationship education aimed at Nepalese youth. Brown et al. (2005) also contend that the mass media should be encouraged to provide more healthy sexual content.

Participants revealed that dating is not limited to single young people. This study found evidence that unmarried girls date married men and unmarried boys date married women. The motives of such dates were frequently linked with either sexual desire or financial advantages. Absent marital partners and economic benefits were key factors for dating and having sex with extramarital partners. The high unemployment levels in Nepal now may contribute to the dating of unmarried boys and girls sex with married partners to ease their financial problems, although pre- and extramarital sexual relations are still a taboo in Nepal (Dahal, 2008; Okazaki, 2002; Puri \& Busza, 2004).

Busy place were good for meeting people on a date, while isolated and quiet places were frequently reported as facilitating factors for sexual intercourse. The literature concurs that there are many opportunities for physical intimacy including sex in romantic partnership (Alexander, Garda, Kanade, Jejeebhoy, \& Ganatra, 2007). Financial motives were also reported for sex by many youths. There were evidences that sex can also be a way to obtain money and gifts from a boyfriend, as found in sub-Saharan Africa (Marston \& King, 2006; Nnko, Chiduo, Mwaluko \& Urassa, 2001).

We suggest that the notion of dating should be incorporated in both formal and informal education. School and colleges are an ideal setting for delivering sex and relationship education and life skills, since it is a simple and easy way to reach a large number of young people (Lee, Chen, Lee, \& Kaur, 2006; Speizer, Magnani, \& Colvin, 2003). Attention should also be given to 
those who do not attend school. Indeed it is a challenging task as it is often difficult to develop a network among young people not attending school (Regmi, Simkhada \& van Teijlingen, 2010).

The findings reveal that young people enter such sexual relationships for a variety of reasons, particularly to fulfil their sexual desires. Financial gain and romantic love are other reasons to undertake pre-marital sexual relations, similarly to a study of young factory workers in Kathmandu (Puri \& Busza, 2004). This highlights that girls in Nepal lack ownership of any property and are deprived of economic activities. Perhaps, for these girls, poverty and the lack of alternative methods of generating income, may affect their decision to turn to sexual activities to fulfil their basic needs.

Some urban boys agreed that young people often visit sex workers. This suggests that urban young people are more vulnerable to STIs. We also found some effect of alcohol on safer sex decisions. This is consistent with a previous study of young people in Nepal (Tamang, Nepal, Puri, \& Shrestha, 2001). Our findings suggest that many young people in Nepal engage in unsafe sex, despite having some access to condoms. One possible explanation is that these young people often decide not to seek family planning because they do not want their parents or community people to know that they are sexually active. Some argued that condoms reduce sexual pleasure during intercourse. Previous studies also documented that the main reasons for not using condoms were loss of pleasure during intercourse and unavailability of condoms (Puri \& Cleland, 2006; Regmi, 2005). This study also documented financial reasons for not using contraceptives. This highlights the need of free delivery of sexual and reproductive health services to young people.

In general, we found richer information in the FGDs than in the interviews. The interaction between FGD participants and the opportunity to hide information may positively 
affect the quality of FGD. On the other side, in the in-depth interviews, the interviewee and the interviewer are facing each other. Focus groups have been successfully used with young people in sexual health studies in places as far apart as Scotland (van Teijlingen et al., 2007) and Mongolia (Roberts, Oyun, Barnasan, \& Laing, 2005), as focus groups promote self-disclosure through mutual support (Kreuger \& Casey, 2000).

This study contained a number of limitations and advantages. The first limitation is that this qualitative study was conducted in some urban and rural areas of two districts of Nepal, making it difficult to generalise about other areas of Nepal. We could not analyze our data on the basis of ethnicity and religion. Being a multi-cultural and multi-ethnic society, Nepal's different cultures and ethnic groups have their own norms and values around sexuality. Hence, our findings may not be transferable to other areas of Nepal. Lastly, as we had to use a discussion guide or topic guide for the training of the interviewers and focus group facilitators the initial thematic analysis follows the topics of the guide quite closely. In the paper these themes or issues are consolidated into more overarching themes. Finally, the key strength of this paper is that it reports on research which is the first of its kind in Nepal.

\section{Acknowledgements}

We would like to thank all participants in Nepal and the interviewers and focus group facilitators who helped us. Finally, we are thankful for the useful comments made by the reviewers and the editor on our initial submission. This study was supported by a grant to the first author from the University of Aberdeen and the Carnegie Trust for Universities of Scotland.

\section{References}


Adhikari, R., \& Tamang, J. (2009). Premarital sexual behavior among male college students of Kathmandu, Nepal. BMC Public Health, 9, 241

Agha, S., \& Rossem, R. (2004). Impact of a school-based peer sexual health intervention on normative beliefs, risk perceptions, and sexual behavior of Zambian adolescents. Journal of Adolescent Health, 24, 441-452.

Alexander, M., Garda, L., Kanade, S., Jejeebhoy, S., \& Ganatra, B. (2007). Romance andSex: Pre-Marital Partnership Formation among Young Women and Men, Pune District, India. Reproductive Health Matters, 14, 144-155.

Ali, T., Ali, P., Waheed, H., \& Memon, A. (2006). Understanding of Puberty and related Health Problems among Female Adolescents in Karachi Pakistan. Journal of Pakistan Medical Association, 56, 68-72.

Altman, D. (2004). Sexuality and Globalization. Journal of National Sexuality Resource Center, $1,63-68$.

Arnett, J. (2002). The psychology of globalization. American Psychologist, 57, 774-783.

Arnett, J. (2010) Emerging adulthood(s): The cultural psychology of a new life stage. In: L.A. Jensen (Ed.), Bridging cultural and developmental psychology: New syntheses in theory, research, and policy. New York: Oxford University Press. 
Aryal, R., \& Adhikary, U. (2003). Adolescent and Youth in Nepal in Population Monograph of Nepal 2000. Kathmandu: National Planning Commission Secretariat.

Axinn, W. (1991). The Influence of Interviewer Sex on Responses to Sensitive Questions in Nepal. Social Science Research, 20, 303-318.

Bhadra, R. (1999). A summary of the most important programme directed to issues of youth reproductive health in Nepal. Kathmandu: BP Memorial Health Foundation.

Bott, S., Jejeebhoy, S., Iqbal, S., \& Puri, C. (2003). Towards adulthood: exploring the sexual and reproductive health of adolescent in South Asia. Geneva: World Health Organization.

Bowling, A. (2002). Research methods in health. Buckingham, England: Open University Press.

Brown, J., Halpem, C., \& L'Engle, K. (2005). Mass media as a sexual super peer for early maturing girls. Journal of Adolescent Health, 36, 420-427.

Burbank, J. (1994). Culture Shock. A Guide to Customs and Etiquette. London: Kuperard Ltd.

Burke, P., Stets, J., \& Pirog-Good, M. (1988). Gender Identity, Self Esteem and Physical and Sexual Abuses in Dating Relationships. Social Psychology Quarterly, 51, 272-285. 
Carver, K., Joyner, K., \& Udry, R. (2003). National estimates of adolescent romantic relationships. In P. Florsheim (Ed), Adolescent romantic relations and sexual behavior: Theory, research, and practical implications (pp. 23-56). Mahwah: Erlbaum.

Choe, M., Thapa, S., \& Mishra, V. (2004). Early Marriage and Early Motherhood in Nepal. Journal of Biosocial Science, 00, 1-20.

Ciairano, S., Bonino, S., Kliewer, W., Miceli, R., \& Jackson, S. ( 2006). Dating, Sexual Activity, and well-Being in Italian Adolescents. Journal of Clinical Child and Adolescent Psychology, 35, 275-282.

Coombs, R., \& Kenkel, W. (1966). Sex Differences in Dating Aspirations and Satisfaction with Computer-Selected Partners. Journal of Marriage and the Family, 28, 62-66.

Dahal, G. (2008). Sexual and contraceptive behavior among men in Nepal: The need for male friendly reproductive health policies and services. Lewiston, NY: Mellen Press.

Doroszewicz, K. (2008). Experience with dating aggression and sexual coercion among Polish college student. Journal of Interpersonal Violence, 23, 58-73.

Esere, M. (2008). Effect of Sex Education Programme on at-risk Sexual Behavior of SchoolGoing Adolescents in Ilorin, Nigeria. African Health Sciences, 18, 120-125. 
Family Health International.(2001). Nepal Adolescent and Young Adult Survey. Kathmandu: Family Health International.

Firth, H. (2000). Focusingon sex: using focus groups in sex research. Sexualities, 3, 275-297.

Forrest, K., van Teijlingen, E., \& Pitchforth, E. (2005). The analysis of qualitative research data in family planning and reproductive health care. Journal of Family Planning and Reproductive Health Care, 31, 40-43.

Francoeur, R., \& Noonan, R. (2004). The Continuum Complete International Encyclopaedia of Sexuality. New York: Continuum. Available from http://www.kinseyinstitute.org/ccies/

Garg, S., Sharma, N., \& Sahay, R. (2001). Socio-cultural aspects of menstruation in an urban slum in Delhi, India. Reproductive Health Matters, 9, 16-25.

Gautam, R. (2004). STD/HIV/AIDS Prevention in Nepalese schools/colleges youths: does peer education work? Paper presented at the International Conference on AIDS, July 11-16, in Bangkok, Thailand.

Gubhaju, B. (2002). Adolescent reproductive health in Asia. Paper presented at the IUSSP Regional Population Conference on South-East Asia's Population in a Changing Asian Context, June 10-13, in Bangkok, Thailand. 
Han, S., Choe, M., Lee, M. \& Lee, S. (2001). Risk-taking behavior among high school students in South Korea. Journal of Adolescence, 24, 571-574.

Hennink, M. (2007). International focus group research. Cambridge: Cambridge University Press.

Hennink, M., Diamond, I., \& Cooper, P. (1999).Young Asia women and relationships: traditional or transitional? Ethnic and Racial Studies, 22, 867-891.

Hennink, M., Rana, I., \& Iqbal, R. (2005).Knowledge of personal and sexual development amongst young people in Pakistan. Culture, Health and Sexuality, 7, 319-332.

Hettrich, E., \& O’Leary, K. (2007). Reasons for their physical aggression in dating relationships. Journal of Interpersonal Violence, 22, 1131-1143.

Isarabhakdi, P. (2000). Sexual attitudes and experience of rural Thai youth. Bangkok: Mahidol University.

Jejeebhoy, S. (1998). Adolescent sexual and reproductive behavior: a review of the evidence from India. Social Science Medicine, 46, 1275-1290. 
Jezl, D., Molidor, C., \& Wright, T. (2005). Physical, sexual and psychological abuse in high school dating relationships: prevalence rates and self esteem issues. Child and Adolescent Social Work Journal, 13, 69-87.

Krueger, A.,\& Casey, M. (2000). Focus Groups. London: Sage.

Lee, K., Chen, Y., Lee, K., \& Kaur, J. (2006). Premarital Sexual Intercourse among Adolescent in Malaysia: A Cross-Sectional Malaysian School Survey. Singapore Medical Journal, 47, 4764871.

Library of Congress .(2010). Country profile Nepal. Retrieved March 2, 2010, from http://lcweb2.loc.gov/frd/cs/profiles/Nepal.pdf

Liu, A., Kilmarx, P., Jenkins, R., Manopaiboon, C., Mock, P., Jeeyapunt, S, et al.(2006). Sexual Initiation, Substance Use, and Sexual Behavior and Knowledge among Vocational Students in Northern Thailand. International Family Planning Perspectives, 32, 126-135.

Marston,C., \& King, E. (2006). Factors that shape young people's sexual behavior: a systematic review. Lancet, 368, 1581-86.

Mathur, S., Malhotra, A., \& Mehta, M. (2001). Adolescent girls' aspirations and reproductive health in Nepal. Reproductive Health Matters, 9, 91-100. 
McCabe, M. (1984). Toward a theory of adolescent dating. Adolescence, 19, 159-170.

McCabe, M. (2005). Boys want sex, girls want commitment: does this trade-off still exist? Sexual and Relationship Therapy, 20, 139-141.

McLellan, E., Macqueen, K., \& Neidig, J. (2003). Beyond the qualitative interview: data preparation and transcription. Field Methods, 15, 63-84.

Mellanby, A., Phelps, F., Crichton, N., \& Tripp, J. (1995). School sex education: an experimental programme with educational and medical benefit. British Medical Journal, 311, 414-417.

Muñoz-Rivas, M., Graña, J., O’Leary, K., \& González, M. (2007). Aggression in adolescent dating relationships: prevalence, justification, and health consequences. Journal of Adolescent Health, 40, 298-304.

Nelson, L., Badger, S., Wu, B. (2004). The influence of culture in emerging adulthood: Perspectives of Chinese college students. International Journal of Behavioral, 28, 26-36.

New Era/Ministry of Health. (2006). Nepal demographic health survey. Kathmandu: New Era.

Nnko, S., Chiduo, B., Mwaluko, G. \& Urassa, M. (2001). Pre-Marital Sexual Behavior among Out-of-School Adolescents: Motives, Patterns and Meaning Attributed to Sexual Partnership in Rural Tanzania. African Journal of Reproductive Health, 5, 162-174. 
Okazaki, S. (2002). Influence of culture on Asian Americans' sexuality. Journal of Sex Research, 39, 34-41.

Pigg, S. (2002). Expecting the epidemic: a social history of the representation of sexual risk in Nepal. Feminist Media Studies, 2, 97-125.

Pitchforth E., \& van Teijlingen, E. (2005). International public health research involving interpreters: a case study from Bangladesh. British Medical Journal, 5, 71.

Pokharel, S., Kulczyki, A., \& Shakya, S. (2006). School-based sex education in Western Nepal: uncomfortable for both teachers and students. Reproductive Health Matters, 14, 156-161.

Poudel, P. \& Carryer, J (2000). Girl-trafficking, HIV/AIDS, and the position of women in Nepal. Gender and Development, 8, 74-79.

Prasai, D. (1999). Effectiveness of sexuality education programme in Palpa district of Nepal. Journal of Reproductive Health, 1, 6-12.

Price, N., \& Knibbs, S. (2009). How Effective is Peer Education in Addressing Young People's Sexual and Reproductive Health Needs in Developing Countries? Children \& Society, 23, 291302. 
Puri, M., \& Busza, J. (2004). In forests and factories: sexual behavior among young migrant workers in Nepal. Culture, Health \& Sexuality, 6, 145-158.

Puri, M., \& Cleland, J. (2006). Sexual behavior and perceived risk of HIV/AIDS among young migrant factory workers in Nepal. Journal of Adolescent Health, 38, 237-246.

Rana, S. (2004). Changing relationships between boys and girls dating. Retrieved April 19, 2009, from http://www.kantipuronline.com/kolnews.php?\&nid=11961

Regmi, P. (2005). Sexual Behavior of Trekking Guides of Nepal. MSc Diss., Aberdeen University.

Regmi, P., Simkhada, P., \& van Teijlingen, E. (2010). ‘Boys Remain Prestigious, Girls Become Prostitutes': Socio-Cultural Context of Relationships and Sex among Young People in Nepal. Global Journal of Health Science, 2, 60-72.

Regmi, P., Simkhada, P., \& van Teijlingen, E. (2008). Sexual and reproductive health status among young people in Nepal: opportunities and barriers for sexual health education and services utilization. Kathmandu University Medical Journal, 6, 248-256.

Reid, J., \& van Teijlingen, E. (2006). Perceptions of school-aged women in northeast Scotlandon sex education: A focus group study. International Journal of Health Promotion and Education, 44, 59-64. 
Roberts, A., Oyun, C., Barnasan, E., \& Laing, L. (2005). Exploring the social and cultural context of sexual health for young people in Mongolia: implications for health promotion. Social Science \& Medicine, 60,1487-1498.

Ryan, G. \& Bernard, H. (2003). Techniques to Identity Themes. Field Methods, 15, 85-109.

Schick, E.(1999). Navajo Wedding Day: A Dine Marriage Ceremony. Cavendish Children's Books.

Silverman, D. (2006). Interpreting Qualitative Data. London: Sage Publication.

Sinha, R. (2008). Building Social Infrastructure. Education and Development, 23, 1-17.

Simkhada, P., Bhatta, P., Regmi, P., \& van Teijlingen, E.(2010).Sexual health knowledge, sexual relationships and condom use among male trekking guides in Nepal: a qualitative study. Culture, Health \& Sexuality, 12, 45-58.

Speizer, I., Magnani, R., \& Colvin, C. (2003). The Effectiveness of AdolescentReproductive Health Interventions in Developing Countries: A Review of the Evidence. Journal of Adolescent Health, 33, 324-348.

Stone, N., Ingham, R., \& Simkhada, P. (2003). Knowledge of sexual health issues among unmarried young people in Nepal. Asia-Pacific Population Journal, 18, 33-54. 
Strange, V., Forrest ,S., Oakley, A. and the RIPPLE Study Team. (2002). Peer-led sex educationcharacteristics of peer educators and their perceptions of the impact of them of participation in a peer education programme. Health Education Research, 17, 327-337.

Tamang, A., Nepal, B., Puri, M., \& Shrestha, D. (2001). Sexual behavior and risk perceptions among young men in boarder towns of Nepal. Asia-PacificPopulation Journal, 16, 195-210.

Tang, S. \& Zuo. J. ( 2000). Dating attitudes and behaviors of American and Chinese college students. The Social Science Journal, 37, 67-78.

Thapa, S., Davey, J., Waszak, C., \& Bhadra, R. (2001). Reproductive health needs of adolescents and youth in Nepal, insights from a focus group study. Kathmandu: Family Health International.

Thornton, A., \& Camburn, D. (1989). Religious Participation and Adolescent Sexual Behavior and Attitudes. Journal of Marriage and the Family, 51, 641-653.

Twinn, S. (1997). An exploratory study examining the influence of translation on the validity and reliability of qualitative data in nursing research. Journal of Advanced Nursing, 26, 418-423.

UNFPA. (2004). Programme of Action adopted at the ICPD, Cairo, 1994. New York: United Nations Population Fund. 
van Teijlingen, E., Reid, J., Shucksmith, J., Harris, F., Philip, K., Imamura, M., et al. (2007). Embarrassment as a key emotion in young people talking about sexual health, Sociological Research Online, 12 (2)

Villarreal, M. (1998).Adolescent Fertility: Socio-Cultural Issues and Programme Implications. Rome: Population Programme Services, United Nations.

Waszak, C., Thapa, S., \& Davey, J. (2003). The influence of gender norms on the reproductive health of adolescents in Nepal-perspectives of youth. In Sarah Bott et al. (Eds), Towards adulthood, Exploring the sexual and reproductive health of adolescents in South Asia (pp. 8185). Geneva: World Health Organization. 
Table 1: Characteristics of focus group participants

\begin{tabular}{|l|l|c|l|l|}
\hline Groups & Participants (N) & Average Age & Education & Place \\
\hline FGD 1 & Girls (8) & 22.6 & $\begin{array}{l}\text { College=6 } \\
\text { University=2 }\end{array}$ & Urban \\
\hline FGD 2 & Girls (7) & 19.2 & School Drop-out=6 & Rural \\
\hline FGD 3 & Girls (8) & 21.5 & $\begin{array}{l}\text { College=6 } \\
\text { University=2 }\end{array}$ & Rural \\
\hline FGD 4 & Girls (7) & 20.4 & $\begin{array}{l}\text { College=4 } \\
\text { University=3 }\end{array}$ & Urban \\
\hline FGD 5 & Girls (6) & 19.3 & School Drop-out=6 & Rural \\
\hline FGD 6 & Boys (8) & 18.1 & College=8 & Rural \\
& & & & Rural \\
\hline FGD 7 & Boys (8) & 20.0 & College=8 & Urban \\
\hline FGD 6 & Boys (8) & & & Urban \\
\hline FGD 9 & Boys (7) & College=8 & \\
\hline FGD 10 & Boys (8) & 19.4 & School Drop-out=7 & College=8 \\
& & 20.3 & & \\
\hline
\end{tabular}


Table 2: Characteristics of interview respondents

\begin{tabular}{|c|c|c|c|}
\hline & Boys & Girls & Total \\
\hline \multicolumn{4}{|l|}{ Age Group } \\
\hline $15-17$ & 1 & 2 & 3 \\
\hline $18-20$ & 5 & 4 & 9 \\
\hline $21-23$ & 8 & 7 & 15 \\
\hline 24 & 2 & 2 & 4 \\
\hline \multicolumn{4}{|l|}{ Education } \\
\hline Secondary & 3 & 1 & 4 \\
\hline College & 10 & 14 & 24 \\
\hline Universities & 3 & - & 3 \\
\hline \multicolumn{4}{|l|}{ Place } \\
\hline Rural & 7 & 5 & 12 \\
\hline Urban & 9 & 10 & 19 \\
\hline \multicolumn{4}{|l|}{ Ethnicity } \\
\hline Brahmin & 8 & 4 & 12 \\
\hline Chhetri & 3 & 4 & 7 \\
\hline Magar & - & 1 & 1 \\
\hline Newar & 2 & 3 & 5 \\
\hline Gurung & 1 & 1 & 2 \\
\hline Marwadi & - & 1 & 1 \\
\hline$V K$ & 1 & - & 1 \\
\hline Rai & - & 1 & 1 \\
\hline Ghale & 1 & - & 1 \\
\hline \multicolumn{4}{|l|}{ Marital Status } \\
\hline Married & 5 & 6 & 11 \\
\hline Unmarried & 11 & 9 & 20 \\
\hline Total Respondents & & & 31 \\
\hline
\end{tabular}

